\title{
The Impact of a Training Program for Families of Students with Learning Disabilities in Activating Familial Participation and Reducing Learning
} Disabilities Aspects and Developing the Academic Achievement of Their Children

\author{
Mohammad Ahmad Beirat ${ }^{1, *}$ \& Akef Abdullah Al-Khateeb ${ }^{2}$ \\ ${ }^{1}$ Special Education Department, College of Educational Sciences, Al-Hussein Bin Talal \\ University, Jordan \\ ${ }^{2}$ Special Educational and Psychological Sciences Department, College of Education, Al \\ al-Bayt University, Jordan \\ *Correspondence: Special Education Department, College of Educational Sciences, \\ Al-Hussein Bin Talal University, Jordan. Tel: 962-775-496-004. E-mail: \\ mohammadbeirat@yahoo.com
}

Received: June 17, 2018 Accepted: August 11, 2018 Published: December 20, 2018

doi:10.5296/ije.v10i4.13872 URL: https://doi.org/10.5296/ije.v10i4.13872

\begin{abstract}
The study aimed at building a training program for the families of students with learning disabilities to activate the familial participation and reduce learning disabilities aspects and develop the academic achievement of such students. The study's sample composed of (46) families and (46) male and female students from these families. To achieve the objectives of the study, the researchers prepared a list to assist the familial participation applied on the families before and after the training period; they used the scale of (Sartawi,1995) to reveal the learning disabilities of their children applied before and after the training period, as well as the scale of academic achievement (educational packages,2010), moreover; they built the suggested program to activate the familial participation. The study concluded that there were statistically significant differences between the pre-measurement and post-measurement in favor of the post-measurement regarding the students' performance in relation to the learning disabilities aspects. It also showed that there were statistically significant differences between the pre-measurement and post-measurement in favor of the post-measurement regarding the students' performance in relation to the academic performance scale (educational packages,2010), furthermore; there were statistically significant positive correlation between the familial participation and learning disabilities aspects, and between the familial participation and the academic achievement.
\end{abstract}

Keywords: Families of students with learning disabilities, Familial participation, Learning disabilities aspects, Academic achievement 


\section{Introduction and Background}

Low school performance is one of the important problems facing families who want their children to have no learning disabilities or an effect on their lives. In case such disabilities are left without intervention to continue beyond school age, they will affect the children's abilities and daily activities, thus; helping those children includes their families' participation, considering that each child with learning disabilities has specific needs just as his family. Learning disabilities bring up challenges for families, therefor; one of the main responsibilities of those working in the field of special education is to achieve the familial participation, seeking for real progress in different areas related to the growth of children with learning disabilities.

Special education literature calls for minding familial training and support, aiming at educating families, providing them with adequate information, training them to form groups that participate in multi disciplinary team, the early family-based intervention, and establishing familial associations. This would not have been possible without creating a strong relationship between the important role that families play in the development of children and the establishment of a participatory relationship between families and specialists(Al-Khateeb, 2009; Heimdahl Mattson, Fischbein, \& Roll-Pettersson, 2010). Training programs dedicated for families have gained a great importance in the special education programs as they give families the skills that will make them influential teachers for their children. Families need a planned educational system in order to identify their interaction with their children which will be beneficial for the child, increase his chances in growing and learning in order to(Ismail, 2012; Mas'udi \& Abd Al-wahab, 2013).

Families need to acquire communication skills that are characterized with trust, respect, care, and being open to professionals and specialists, add to this; the skills of resolving disputes and being aware of the issues of students with learning disabilities, the matter that would bring the effective participation of educators and specialists so students benefit of this in different aspects. (Al-Hiary, 2012).

The process of achieving growth in the different aspects of the personality of the student with learning disabilities is an urgent goal for all modern educational systems (Al-Zayat, 2007), as for there is an emotional and social mal-adjustment where they are inchined to Introversion depression, and forming a negative image of themselves (jirar, Al-Miladi, 2008); (Hanafi, Rafeeq, 2010).

Modern studies show that there are several integrated reasons for learning disabilities. The role of specialists in planning societal and familial training programs (Learner, 2003), is referred to in (Al-Rosan, 2010), and activating the familial participation have a great importance and an effective role in encouraging learning. Families need to have enough opportunities to participate in their children's learning activities. Families who achieve efficiency in their children's learning need to be provided with information, training programs, and guidance that will benefit them. They also need support from the special education teachers (Almakanin, Al-Zo'ibi, \& Beirat, 2018) in order to overcome the psychological pressure they have due to their children's situation, so they reach a 
psychological relief that will give a room for a better participation that enhances the academic achievement of their children(Grossman, 2010), Families feel comfort toward the development achieved by their children, family members will be seen as an effective active members to train their children and that they are the most capable of supporting the children in their learning stages, planning and choosing the suitable educational alternative, and achieving a remarkable development regarding the social and personal growth (Guralnik, 1997). They also need to understand the child's situation deeper and more accurate, and know what to expect in the child's future, know the information related to the child's needs and how to help him fulfilling them, the child's growth stages, the information related to services and aid provided by the local community, and the information regarding educating children and providing them with the basic academic skills. (Eheart \& Ciccone, 1982). Families need to understand the nature of the programs provided to their children in order to participate in the decisions related to them, in the multidisciplinary team, and in the individual educational planning. (McDonnall, Cavenaugh, \& Giesen, 2012). They also need to be informed about their children enhancement during the academic year, as they worry for their children's academic, social and emotional development. These needs can be met through holding regular reunions with parents, organizing informative meetings with collective discussions (Al-Sartawi \& Al-Sartawi, 1988). Moreover, through a set of guidelines, processes and manners represented by supporting the child growth, reducing the family's stress, building cooperation relationships, communicating and interacting respectfully with the family, providing families with official support resources, and respecting the familial needs aiming at achieving balance and providing the emotional support (Da'na, 2011).

Educational literature mentions that the better the familial participation is the better the child's response becomes. Activating the familial participation depends on three basic principles which are: the familial participation is more successful than the intensive training focused on the children with learning disabilities; the effects of the familial participation in planning programs, decision making, and the level of development appear on the children; and providing services in a way that takes the families need into consideration affects children positively leading to quantitative and qualitative benefits. (Da'na, 2011 p.66)

Educational and psychological studies confirm that the social environment in which a student lives has a great importance in the educational process. The parent's care for educating their children, their constant motivation, and the time allocated for doing their homework play an important effective role in the academic achievement. (Al-Shahrani, 1996) points out that family's stability and interdependence are effective factors in the achievement of students with learning disabilities, and families who suffer problems and familial disputes, where fathers and mothers treat their children harshly affect the students eagerness for learning and their academic achievement.( Al-Sinani, 2005) He added that family's educational and economic level has a positive correlation with the academic achievement. As a result, the most successful training programs are those based on training the families and the students, considering familial participation as the input behavior to solve learning disabilities, as well as respecting the families' view on the choice of goals in determining the educational program (Taylor, 2006). 
Finally, this study came to highlight an important subject specified by studying the effect of using a training program dedicated for the families of students with learning disabilities, its impact on reducing the learning disabilities aspects among the study sample, increasing the academic achievement of the children, and activating their families participation in the program.

\subsection{Problem of the Study}

The problem of children with learning disabilities is not limited to the children themselves but also include the family as well. The existence of a child with learning disabilities in a family poses unexpected responsibilities on its members.

Recent legislation suggests that the involvement of families in the education of children with learning disabilities is a legislative requirement and a consensus among the workers in special education field (Almakanin, Al-Zo'ibi, Beirat, 2018). Special education specialists emphasize that as long as no one knows the main cause of learning disabilities, parents' attempts of continuous search for the possible reasons are not useful to them. But more importantly, a family must move forward in order to reach the best treatment for their children by acquiring the necessary training skills. Although learning disabilities have an academic impact, they go beyond the academic fields. It is not enough to deal with academic difficulties in isolation from the social aspects and family's training needs, where families take the role of the participating teacher who assures the knowledge, develops the services and makes the decisions. Therefore, the present study sought to clarify the role played by the training programs in raising the level of development of academic achievement among students with learning disabilities, reducing learning disabilities aspects and activating the familial participation.

\subsection{Questions of the Study}

1- Is there a statistically significant difference at $(\alpha \leq 0.05)$ among the means of the families' performance on the list of the pre-measurement and post-measurement of the participation assessment?

2- Is there a statistically significant difference at $(\alpha \leq 0.05)$ among the means of reducing the learning disabilities aspects according to the pre-measurement and post-measurement?

3 - Is there a statistically significant difference at $(\alpha \leq 0.05)$ among the means of the students' academic achievement according to the pre-measurement and post-measurement of academic achievement (educational packages)?

4- Is there a statistically significant relationship at $(\alpha \leq 0.05)$ between the familial participation and reducing learning disabilities aspects?

5 - Is there a statistically significant relationship at $(\alpha \leq 0.05)$ between the familial participation and the development of academic achievement?

\subsection{Objectives of the Study}

Achieved by building a training program for the families of students with learning disabilities 
and identifying its effect in activating the familial participation, reducing learning disabilities aspects and developing the academic achievement of their children, moreover; directing workers in special education to the role of familial participation and enhancing its activation and importance in fulfilling the needs of academic students with learning disabilities. The detailed objectives of the study represented in developing the manner of academic achievement and the familial participation, motivating the school management and the faculty to interact positively with the program, moreover; encouraging parents to participate positively and accept the procedures of the programs which activates the familial participation, reduces learning disabilities aspects and develops the academic achievement.

\subsection{Importance of the Study}

This study cares for families of students with learning disabilities. The overall importance of the study can be put as follows:

1- The possibility of using its results in helping those responsible for planning and implementing educational policies of students with special needs.

2- Teachers benefit from its results in using some learning strategies and minding the familial participation in teaching students with learning disabilities.

3- Students of higher education and researchers in the field of special education may benefit from the tools of the study in their researches and studies.

4- Highlighting the role of familial participation in limiting learning disabilities aspects among students especially in the first basic stage.

\subsection{Limitations of the Study}

The current study is limited with the time frame in which it was conducted, from 20/9/2016 to 20/11/2016, during the first semester of the academic year 2016/2017within the Directorate of Education in Ma'an-Jordan, The results of the study are limited according to the following determiners:

1- The study members: students with learning disabilities at the third grade of the academic year (2016/2017).

2- The effect of the training program in activating the familial participation, reducing learning disabilities aspects and developing the academic achievement for students with learning disabilities by using the scale of learning disabilities (Sartawi Scale,1995), and the list of the used familial participation assessment, as well as the scale of academic achievement (Educational Packages,2010) for the basic third grade.

3- The accuracy of the families' responses over the items of the familial participation assessment list.

4- The procedural limitations and terms.

5- The practical applications of the results of this study. 


\subsection{Procedural Definitions}

Training program is the program designed to activate the familial participation of students with learning disabilities. The program is composed of a set of trainings, activities and designed educational experiences that would allow families the opportunity to acquire the needed skills to activate their participation; they will be educated in the light of training situations (texts) chosen for the training activities, in addition to sessions that achieves participation and to inform them with the needs of their children with learning disabilities.

Families of students with learning disabilities it is a general term which refers to a heterogeneous group of families whose children have a form of developmental and academic learning disabilities such as calculation processes, basic literacy skills or cognitive processes (memory, concentration, recognition, attention) or the ability to listen or perceive, think and talk (Jarwan, Al-Khamra, Sadeeq, Tabbal, 'amayra, Maqdadi, aliwat, Al-Ali, Al-Hiary, Fawaz, Al-Zara', Al-Jabiri, 2013). In this study, they are the families whose children have been sent to the resources rooms, who are participating in the sessions of the training program designed for their children needs. Moreover, where the class teacher, the school principle, the educational guide and the special education teacher indicate that the children of those families have a disorder in one or more of the psychological processes related to written or spoken language.

Familial participation: is the total level of participation achieved by a family (mother, sister, or who follows the student with the learning disabilities) on the scale of familial participation (the list of familial participation assessment), it handles the real opportunities to participate and to be informed about the training needs of their children which enhances the development of the children with learning disabilities through the activities and skills of the training program designed to activate the familial participation.

Learning disabilities aspects are the set of the academic, behavioral, cognitive, and dynamic difficulties that students with learning disabilities have according to the scale of learning disabilities (Sartawi, 1995). This is measured in this study according to the total score of the pre-measurement and post-measurement achieved on the scale from (1-5).

Academic achievement is the total score achieved by the student with learning disabilities according to the academic achievement (educational packages, 2010), measured in this study according to the score that children with learning disabilities achieve according to the educational packages in both applications.

\section{Previous Studies}

Families' participation represents an effective communication that results in positive satisfaction towards both the student and the school, so studies will be mentioned in a chronological order from the oldest to the newest, related to the variables of the current study.

Alderte Phan(2002) conducted a study aiming at comparing the responses of children with and without learning disabilities and comparing the stress responses of children with and 
without learning disabilities. Self-expression scale for children has been used so do the test of determining stress within a school situation. The study sample was composed of 6 to 12 year-old students belonging to poor, medium and rich social classes. The results showed that students with learning disabilities receiving special education services have achieved negative results in learning responses compared to their peers who don't have learning disabilities. The study concluded that teachers are aware of the students stress and the applied strategies to overcome the problems they have.

The study of Agnew, Dorn, and Eden (2004) aimed at measuring the impact of intensive training through a treatment program over audio processing and reading skill. The study sample consisted of 7 children. The children's ability to accurately judge visual and audio stimulants have been tested before and after the treatment program which aims at improving their reading skills. Children have shown significant improvement in hearing processing after therapeutic intervention, which let us generalize the improvement in hearing processing on reading skills training as well.

The study of Abu Zaitoun (2004) pointed out building a training program about the studying skills of students with learning disabilities, and measuring the development of their studying skills and academic achievement. The study sample consisted of (68) male and female students with learning disabilities in math and reading, from the third and fourth grades in Jordan. The researcher used the scale of studying skills and achievement tests. The results showed that there were statistically significant differences in the academic achievement in favor of the experimental group attributed to the training program used in studying.

The study of Hasouneh (2004) aimed at identifying the effectiveness of a training program for social skills in developing self-concept in different dimensions as one of the aspects of learning disabilities. The study sample was made of (26) students, divided randomly into two harmonious groups of the sixth, seventh and eighth grades. The experimental group was offered a training program in social skills. The results revealed that there are statistically significant differences in favor of the experimental group in self-concept with all its dimensions.

Carlson \& Hopper (2004) conducted a study aimed at identifying the impact of a training program in enhancing the academic achievement of a group made of (15) students with learning disabilities, their ages vary between $(9-11)$ years old, over which a pre-measurement and post-measurement of achievement have been applied. The training program was composed of activities that improve self-perception in academic fields. Among the most important results was the effectiveness of the training program used in studying to enhance the academic achievement of the members of the study sample.

Al-Batal (2005) conducted a study applied on the teachers of students with learning disabilities in which he pointed out that students vary in their capabilities, disabilities aspects, needs, and cultural backgrounds. In this case, the teacher feels a sense of helplessness in the classroom, Insufficient training and preparation (before and during service) led teachers of learning disabilities to feel regret and job dissatisfaction, which is one of their main sources of psychological burnout. 
Al-Kurdi (2006) carried out a study aiming at identifying the most important contemporary experiences in the field of community participation in the educational process, where he examined the community participation in the educational process in Riyadh city, moreover; identifying the role of community participation in the development of educational institutions. The study sample composed of workers in the educational field, educational experts, workers in institutions, companies and local associations, and students' parents. One of the most important results of this study is that more than half of the foundations and the fields of community participation for the development of educational institutions in Riyadh are incomplete and unrealized in reality and they need to be more activated in order to benefit from this participation. Suggested perceptions of the roles of members and institutions which contribute in the community participation have been presented as well. One of the most important recommendations of the study was to highlight the importance of the participation of the community in the educational field as well as to develop various mechanisms to achieve this and to work on setting the required educational systems to activate participation in the educational field. Moreover; activating the familial participation in the development of educational institutions, encouraging the participation of local communities to achieve effective participation in the development of education and its various institutions, and activating the different roles of family meetings to activate the participation in educational meetings.

Alice and Alan (2011) carried out a study under the title: the impact of parents' intervention in the education of children with learning disabilities in reading and writing over their academic achievement. Researchers have applied a measurement-based methodology. The sample of the study was made of (22) children. The results showed that the majority of the children became more fluent and accurate in reading, have acquired more vocabularies, and became better in their writing skills. The results also showed that the parents' participation and cooperation with school and teaching at home led to improve their children's skills, which was reflected on their academic achievement.

Zhang, Hsu, Kwok, Benz, Bowman-Perrott (2011) conducted a study aiming at testing the variables associated with race/ethnicity and socioeconomic status and their impact on the parental relationships at school and at home and how this affects school activities, the expectations from a child, and his academic achievement. The most important results of this study were the positive impact of relations at home over the student's achievements, and that participation in the school activities didn't have a significant effect on the students' achievement.

Hidrous \& Al-Farra (2011) conducted a study aimed at identifying the impact of using active learning strategies on motivation, self-confidence and academic achievement levels. The study sample composed of (80) students with learning disabilities divided into two experimental groups made of (40) students. The results of the study showed that there were statistically significant differences in the pre-application and post-application of the achievement motivation scale and the self-confidence scale, in favor of the post-application, And that there are statistically significant differences between the two experimental groups regarding the achievement tests in Arabic and mathematics, as well as there is a positive 
correlation between the level of the academic achievement in Arabic and mathematics and the level of self-confidence. The study recommended conducting other studies on students with learning difficulties in other areas with the need to assist them in their practical lives and prepare for them special remedial programs.

Ulaimat \& Al-Fayiz (2012) carried out a study aimed at investigating the effectiveness of a training program to develop the academic skills of children with language disorders. The study sample composed of (20) children divided equally into two groups: a standard group and an experimental group subject to the language skills development program. The results showed statistically significant differences between males and females in the development of receptive language skills, in favor of females. On the other hand, the two way analysis of variance showed that the effectiveness of the treatment program varies by gender, as for females showed an improvement in the skill of receptive language better than males during the treatment program.

Ukeli \& Akem (2013) studied the effect of parents on the achievement in mathematics for students with visual disability. He studied the impact of parents' intervention on achievement; the relationship between parents' participation at home and school, and achievement in mathematics for students with visual disability. The study sample composed of (215) students, models of different levels have been used to answer the study's questions. The results showed that the type of parental participation was related to mathematics achievement and played a positive role in it for students who started their studies in the basic regular school. The study also showed that the role of parents at home was negative regarding the students' academic achievement in mathematics. There was also a strong positive relationship between parents' participation at home and the mathematics achievement of students with visual disabilities.

Al-Makaneen, Abdullat \& Al-Njadat (2014) have carried out a study aimed at identifying behavioral problems of students with learning disabilities and its relation with social competence from the teachers and peers' point of view. The sample of the study consisted of (135) male and female students with learning disabilities enrolled in the resources rooms at schools subject to the education directorates in the southern region. The study scales was constructed in two forms, one for teachers and the other for ordinary students in order to judge the behavioral problems in cases of learning disabilities. Walker-McConnell scale was used for social competence and school adjustment. The results of the study showed that the most common behavioral problems for students with learning disabilities are problems related to the dimension of hyperactivity accompanied with attention deficit, followed by problems related to the withdrawal dimension, and then problems associated with the dimension of stubbornness and the dimension of aggression. The least common behavioral problems were related to the dimension of dependence. Then the problems associated with stubbornness, dependence and the behavior associated with the withdrawal dimension, and the least common behavioral problems are associated with the dimension of aggression. The results indicated a high degree of social competence for students with learning disabilities in areas related to their participation in laughter, play and talk with their peers, and a low degree when it comes to using leisure time in an appropriate manner. 


\section{Mll Macrothink}

International Journal of Education

ISSN 1948-5476

2018, Vol. 10, No. 4

Poon-McBrayer and McBrayer (2014) conducted a study that handled the Chinese parental experiences in supporting their children with learning disabilities (Dyslexia). The study sample composed of (25) children and their parents. The results showed that parental support reduces self-blame and sadness among children and increases their knowledge and abilities. The results also indicated that the parents' opinions towards teachers' wrong practices in the class and the inefficiency of teaching methods have a negative impact over the children abilities of academic achievement.

Afolabi (2014) conducted a study with the title of: the Parental participation in the comprehensive education, an experimental test for the development of students with special psychological and educational needs. The study highlighted the concept of parental participation and the possibilities of its achievement in tangible context regarding the comprehensive education. The study included a presentation of the experimental literature which clarifies the interaction between parental participation, comprehensive education and the students' achievement. It also includes structuring models that connect between the parental participation and the children's psychological and educational development, as well as using the perspectives of environmental development and the model of Hoover-Dempsey and Sandler (1995) to analyze and clarify the interaction between the parental participation and academic achievement, what parents believe, the experiences and expectations which all are considered as important factors to support the outputs of a better education for children of special needs.

Thrnton (2015) carried out a study handled the relationship between parents participation and the academic achievement of students with special needs. The study aimed at focusing on homework and the parental participation in the homework of students with special needs. This study was designed to analyze the parents and teachers' beliefes in the parental participation in their children's homework. Parents of the first grade students in Chicago school and the teachers have participated in this study. Data has been collected through a questionnaire distributed over the parents and teachers.

\subsection{Commenting over the Studies}

The current study comes as a response to the recommendations on academic achievement, familial participation, and the reduction of learning disabilities aspects, separately. There are several studies that link between the parental participation and the students' academic achievements in general, but only few studies handled this issue in the field of special education. Most of the studies that investigated familial participation in general have contained several types of familial relations therefor it is hard to estimate the impact of some familial relations and learning disabilities aspects. The current study came to reveal the impact of the program designed for activating familial participation, reducing learning disabilities aspects and developing the academic achievement as the researchers have not found, up to their knowledge, any study that handled these variables together at the same time or handled the relationship between developing the level of academic achievement, reducing learning disabilities aspects that lead to learning disabilities and the familial participation in developing students with learning disabilities. As a result, the current study was unique in 
revealing these relationships through developing a training program for the families of students with learning disabilities to activate their participation and identify the level of its contribution in the development of the academic achievement and the reduction of learning disabilities aspects for students with learning disabilities.

\section{Methodology of the Study}

The researchers followed a semi-experimental approach through applying the pre and post measurement over one group.

\subsection{Tools of the Study}

A- The list of familial participation assessment, its validity, reliability and correction: the List is characterized by its validity through handling the topics of familial participation; the content validity through arbitrators specialized in curriculums, general teaching methods and special education; they were (9) arbitrators from Al-Hussein Bin Talal University; and discriminant validity which led to the omission of (3) items, in addition to the clarity of the familial participation items, its harmony and language correctness. The reliability of the list has been verified through calculating the internal consistency using Cronbach's Alpha coefficient which has the value of (0.76), and the repetition reliability over an exploratory sample from outside the sample of the study made of (30) members, after two weeks of the application with the value of (0.76) which is considered appropriate for the objectives of the current study. The final form of the familial participation list have been reached with (23) items. The list has been corrected by giving one mark for each item of the list using an assessment scale of three levels (most of the times, sometimes, rarely) with grads from (1 to 3 ), where the highest score of the list is (69) and the lowest score is (23).

B- Sartawi Learning Disabilities Scale (1995), its validity, reliability and correction: it is a scale for learning disabilities designed by Zeidan Sartawi. It is composed of (50) items using Likert scale. These items are divided into three dimensions; the academic disabilities: the ability to understand, assess and express self-emotions within societal context in an appropriate manner, composed of (25) items carrying the numbers (1-25); the behavioral aspects: the ability to amend, organize and control emotions to achieve the successful social interaction, made of (12) items carrying the numbers (26-37); and cognitive hyperactivity difficulties: the ability to deal voluntarily with others on the social and emotional levels with confidence and controllability, composed of (13) items carrying the numbers (38-50).

The scale in its original form is characterized with the validity characteristics within the Jordanian environment, such as the construct validity and content validity. Moreover, it is reliable as the scale for the current study with its form within the Jordanian environment. The reliability of this scale has been verified by the researchers through applying it over an external sample composed of (30) members. The reliability of the scale has been calculated in two ways; using the test-retest method as an indicator for the reliability (repetition), and Cronbach's Alpha coefficient as an indicator for the internal consistency. The time interval between the two applications was two weeks. Table (1) shows the reliability coefficients of 
the scale. The indications of the scale's reliability was considered sufficient for the purposes if this study.

Table 1. Reliability Coefficients of the Scale of Learning Disabilities Aspects

\begin{tabular}{cccc}
\hline Dimension & $\begin{array}{c}\text { Reliability of } \\
\text { Repetition }\end{array}$ & $\begin{array}{c}\text { Reliability of } \\
\text { Consistency }\end{array}$ & Number of items \\
\hline Total & 0.88 & 0.86 & 50 \\
\hline
\end{tabular}

To know the level of the reduction of learning disabilities aspects among the study sample, the score that the students get answering the scale's (50) items is distributed over three main dimensions: the first is the academic disabilities dimension composed of (25) items, the second is the behavioral aspects dimension composed of (12) items, and the third is the dimension of hyperactivity cognitive difficulties composed of (13) items. The scale is corrected by giving one mark for each item of it by using Likert scale of assessment (Applicable to a very high degree, applicable to a high degree, applicable to a medium degree, applicable to a low degree, applying very poorly) with degrees from (1 to 5) representing the aspects of academic, behavioral, cognitive and hyperactivity disabilities. Grade (5) is given to (applicable to a very high degree), where the highest score of the scale would be (250) and the lowest (50).

C- The Scale of Academic Achievement (the achievement test) of the Ministry of Education (2010): the test composed of two parts: the first is about Arabic language composed of (28) educational goals, covers the basic knowledge requirements that a student should have according to his class and related to the Arabic curriculum of the third grade/ first semester (Arabic language package). The second is about mathematics of the third class/ first semester (mathematics package), composed of (89) educational goals, covers the basic knowledge requirements that a student should have according to his class and related to the curriculum of mathematics of the third grade/ first semester. This test is considered one of the official tests as for it is supervised and prepared by the ministry of education in its different governorates in Jordan, as a result it enjoys the construct validity and face validity. The reliability coefficient and internal consistency of the scale have been calculated using (Richardson formula 20$)$ and had the value of (0.85). The repetition reliability coefficient was calculated according to Spearman Brown formula and had the value of (0.91) over an exploratory sample from outside the sample of the study composed of (30) members. The values were considered as sufficient for the purposes of the current study.

D- The training program designed for families:

First: building the training program, determining its theoretical base and validity: the researchers depended in building the training program on the subject of familial participation and finding ways for such a participation, confirmed by the Education of All Handicapped Children Act, that are supposed to enhance the opportunities of familial participation. Special 
education programs are not limited to offering services to students but also to their families as well. A training program has been designed to address a number of activities and skills that enable families to learn about their children's educational needs (child centered relations) and the family's interrelationship with the school framework, ordinary teachers, special education teachers, and other families who participate in their children's disabilities the educational environment (the classroom environment), where the forms of participation can be through activities related to the follow-up register, daily and weekly examination reports, telephone calls, parents meetings and communication with specialists who are supposed to fulfill the educational needs of their children, build in the parents the confidence and familiarity in dealing with their children, being able to understand problems, and deal realistically with strengths and weaknesses. Taking account the individual differences of their children and the efforts made by teachers of special education, the tasks of educational programs, the methods and means to provide them with the adequate development, which can be achieved through the effective participation guaranteed by the list of familial participation assessment prepared in advance. The program was presented to 13 faculty members as arbitrators from Al-Hussein Bin Talal University and (3) female teachers who teaches in the resources room aiming at receiving any suggestions for developing the program. After applying the suggested amendments of addition and omission, the program was applied over the allocated schools in the first semester of the academic year 2016/2017 over a period of two months starting from 20/9/2016 until 20/11/2016, with 5 training visits for each of the (5) schools, with (45) minutes duration of training per session. The sessions are divided into the application of the three tools of the study (the scale of aspects, participation and achievement), in addition to the training program of families, including the preliminary meeting and the final meeting.

Second: identifying the goals of the program: the training programs aims at achieving the following goals:

1- The impact of the presented training program.

2- Assessing the level of the participation of families with their children of learning disabilities.

\section{3- Activating the familial participation.}

4- Using the level of academic achievement to indicate the impact of familial participation.

5- The importance of training programs addressed to the families of the students with learning disabilities, the development of their academic achievement and reduction of learning disabilities aspects.

Third: The content of the training program: at this level, training visits were organized aiming at training the families of students with learning disabilities at the five allocated schools. A unified framework for the session was adopted, which includes the objectives of the session, the materials needed to implement the content of the session, a procedural description of the activities to be followed to learn the capacities of interest, and homework. The sessions were designed in a way that interests families and increases their work with the progress of the 
activities, including the instructions and procedures of applying the activity. The activities of the training program are provided through the following strategies: role-playing, discussion, story, feedback, self-reflection, teamwork, and imagination. The researchers also used many tools such as personal pictures, stories, and television scenes. The skills included are represented in strategies for teaching Arabic language and mathematics, as well as a familial guidance and behavioral aspect (individual and collective guidance), including guidance sessions and an applicable behavioral analysis.

\subsection{Procedures of the Study}

The study was conducted according to the following phases:

1- Obtaining the approval of the Directorate of Education in the Ma'an region and addressing the schools' managements from which the study sample was selected, and talking to the principle and teachers of each school about the study and its objectives in order to provide the necessary facilities for the application of the study's tools over the third grade students and for the training program sessions for the families of students with learning difficulties.

2- Applying the pre and post scale of learning disabilities aspects (Sartawi scale,1995) and correcting the answers.

3- Applying the pre and post test of academic achievement (educational packages,2010) of the students with learning disabilities and correcting the answers.

4- Applying the pre and post scale of the participation of families of students with learning disabilities and correcting the answers.

5- Applying the training program during the first semester of the academic year 2016/2017, over a duration of two moths with (5) training visits per school.

6- Supervising the program to guarantee its correct application though the assistance of the third grade teachers and addressing questions to families during and after the application.

7- Analyzing the data, reaching the results and presenting scientific explanations.

\subsection{Members of the Study}

The study population consists of all students with learning disabilities who are enrolled in the resources rooms, diagnosed as having learning disabilities, distributed over all the schools of the Directorate of Education in the Ma'an Region, on the first semester of the academic year (2017/2016). The population is made of (263) male and female students according to the statistics of the general education department of the Directorate, distributed over (16) schools. The purposive sample of the study consisted of (46) families and their 46 male and female children enrolled in the resource rooms, and were transferred by the classroom teacher and the school management to the resources room teacher. They are the third grade students at Umm Al-Hakam Primary Mixed School, Al-Shameya Primary Mixed School, Ma'an Primary Mixed School, Nusseibah Al-Maziniyah Mixed School and Khadija Bint Khuwailid Primary Mixed School. Table (2) shows the distribution of the study sample over the schools in which the opportunities of cooperation among teachers, school management and families are 
available in order to apply the program.

Table 2. Distribution of the Study Members over the Cooperating Schools

\begin{tabular}{lccc}
\hline \multicolumn{1}{c}{ School name } & Males & Females & Total \\
\hline Umm Al-Hakam Primary Mixed School & 6 & 3 & 9 \\
Al-Shameya Primary Mixed School & 5 & 3 & 8 \\
Ma'an Primary Mixed School & 3 & 3 & 6 \\
Nusseibah Al-Maziniyah Mixed School & 7 & 5 & 12 \\
Khadija Bint Khuwailid Primary Mixed School & 4 & 7 & 11 \\
Total & 25 & 21 & 46 \\
\hline
\end{tabular}

\section{Results and Discussion}

This saction include the results that were achieved by answering the questions of the study as follows:

To answer the question of "Is there a statistically significant difference at $(\boldsymbol{\alpha} \leq \mathbf{0 . 0 5})$ between the means of the families' performance according to the pre and post measurement of the familial participation assessment list?" the arithmetic means and standard deviations have been calculated for the families' performance according to the pre and post measurement of the familial participation assessment list. To identify the statistical differences between the arithmetic means, T-test has been used for the correlated data. The table below shows this.

Table 3. Means, Standard Deviations, and t-test Results of the correlated data between the Pre and Post Measurement of the Families' Performance According to the Familial Participation Assessment List

\begin{tabular}{llllllll}
\hline & Measurement & N. & M & SD & T & df & Sig. \\
\hline Familial participation & Pre & 46 & 38.20 & 10.664 & -7.484 & 45 & .000 \\
assessment & Post & 46 & 45.59 & 11.748 & & & \\
\hline
\end{tabular}

The table shows that there are statistically significant differences at $(\alpha \leq 0.05)$ between the pre and post measurement, where the $t$ value was (7.484) with a statistical significance of (.000). The differences were in favor of the post-measurement.

To answer the question of "Is there a statistically significant difference at $(\boldsymbol{\alpha} \leq \mathbf{0 . 0 5})$ between the means of the pre and post measurement of the scale of the reduction of learning disabilities aspects?" the arithmetic means and standard deviations of the pre and post measurement of the reduction of learning disabilities aspects have been calculated. To identify the statistical differences between the arithmetic means, T-test has been used for the 
correlated data. The table below shows this.

Table 4. The Arithmetic Means, Standard Deviations, and T-test of the Correlated data between the Pre and Post Measurement of the Students' Performance Regarding the Aspects of Learning Disabilities

\begin{tabular}{llllllll}
\hline & Measurement & $\mathrm{N}$ & $\mathrm{M}$ & $\mathrm{SD}$ & $\mathrm{T}$ & $\mathrm{df}$ & Sig. \\
\hline Learning & Pre & 46 & 172.35 & 63.097 & 7.074 & 45 & .000 \\
disabilities & Post & 46 & 153.52 & 63.204 & & & \\
aspects & & & & & & & \\
\hline
\end{tabular}

The table shows that there are statistically significant differences at $(\alpha \leq 0.05)$ between the pre and post measurement, where the $\mathrm{T}$ value was (7.074) with a statistically significance of (0.000). The differences were in favor of the post-measurement.

To answer the question of "is there a statistically significant difference at $(\boldsymbol{\alpha} \leq \mathbf{0 . 0 5})$ between the means of pre and post measurement of the students' academic achievement scale (educational packages)?" means and standard deviations of the pre and post measurement of the students' academic achievement scale (educational packages, 2010) have been calculated. To identify the statistical differences between the arithmetic means, T-test has been used for the correlated data. The table below shows this.

Table 5. The Arithmetic Means, Standard Deviations, and T-test of the Correlated Data between the Pre and Post Measurement of the Students' Achievement on the Academic Achievement Scale

\begin{tabular}{|c|c|c|c|c|c|c|c|}
\hline & Measurement & $\mathrm{N}$ & M & $\mathrm{SD}$ & $\mathrm{T}$ & df & Sig. \\
\hline Academic & Pre & 46 & 61.59 & 21.335 & -6.094 & 45 & .000 \\
\hline achievement & Post & 46 & 65.78 & 21.484 & & & \\
\hline
\end{tabular}

The table shows that there are statistically significant differences at $(\alpha \leq 0.05)$ between the pre and post measurement, where the $\mathrm{T}$ value was (-6.094) with a statistically significance of (0.000). The differences were in favor of the post-measurement.

To answer the question of "is there a statistically significant relation at $(\alpha \leq 0.05)$ between the familial participation and the reduction of learning disabilities?" Pearson's correlation coefficient between the familial participation and the learning disabilities aspects has been calculated. Table (6) shows this. 
Table 6. Pearson's Correlation Coefficient between the Familial Participation and the Learning Disabilities Aspects

\begin{tabular}{lll}
\hline & & Learning disabilities aspects \\
\hline Familial-participation & $\mathrm{R}$ & $* * .542$ \\
assessment & $\mathrm{Sig}$. & .000 \\
& $\mathrm{~N}$. & 46 \\
\hline & $* *$ statistically significant at $(0.01)$
\end{tabular}

From the correlation coefficient above we see that there is a statistically significant positive correlation between the familial participation and the learning disabilities aspects.

To answer the question of "Is there a statistically significant relation at $(\alpha \leq 0.05)$ between the familial participation and the development of academic achievement?" Pearson's correlation coefficient between the familial participation and the academic achievement has been calculated. Table (7) shows this.

Table 7. Pearson's Correlation Coefficient between the Familial Participation and the Development of the Academic Achievement

\begin{tabular}{|c|c|c|}
\hline & & Academic achievement \\
\hline \multirow{3}{*}{$\begin{array}{l}\text { Familial } \\
\text { assessment }\end{array}$} & participation $\mathrm{R}$ & $* * .635$ \\
\hline & Sig. & .000 \\
\hline & N. & 46 \\
\hline
\end{tabular}

From the correlation coefficient above we see that there is a statistically significant positive correlation between the familial participation and the academic achievement.

The study reached a number of results related to the goal of the study. The result related to the first question showed that there are differences between the pre and post measurement in favor of the post measurement. The researchers attributed this result to the importance of the program and its role in activating the performance of families in participation, as well as it has the efficiency in dealing with families and increasing their knowledge of the psychological and academic needs of their children. The increment in the level of familial participation made them more able to handle the pressures they face while dealing with their children. The program's ability to provide families with the activities, methods and means that meet their individual needs makes participation better and achieves positive aspects regarding gaining the ability to make decisions, realizing the individual differences and the realistic understanding of the development of their children. Moreover, the families' cooperation and seriousness in dealing with the prepared program assured their participation and its effects. Therefore, activating participation leads to acquiring the ability of dealing within the school framework after reviewing the efforts made by the teacher of special 
education and his duties within the resource room which made understanding the achievement's abilities one of the fulfilled goals of the program designed for the purposes of this study. This goes with the study of (Al-Kurdi, 2006) which recommended activating the familial participation in developing the educational institutes, achieving the effective participation in the educational institutions, activating the different roles of families meetings to activate the participation in the educational meetings.

Results related to the second question showed that there are differences between the pre and post measurements in favor of the post measurement indicating the impact of the training program in reducing learning disabilities aspects represented by the overall dimensions measured by Sartawi scale of learning disabilities which dealt with three dimensions: the academic disabilities represented in the ability to understand, assess and express self-emotions; the behavioral aspects represented in the ability to adjust, organize and control emotions and behavior to achieve the successful social interaction; and the cognitive and hyperactivity disabilities represented in the ability to deal voluntarily with other people on the social and emotional levels with confidence; moreover; an enhancement in the disabilities that the students suffer from as indicated by the result as for the training program has an impact on reducing their learning disabilities aspects. The researchers explain this result by the fact that training programs have an importance in activating the students' performance, interaction and activity which lead to developing their abilities and reducing learning disabilities aspects. The increment of motivation through these training programs increases their motivation of achievement and enables them to create competitive opportunities among the participating families in the training programs. Therefore, familial training programs and participation activation have a positive impact on the reduction of learning disabilities aspects which was confirmed by this result. This agrees with the study of (AL-Makaneen et al., 2014) which handled an assessment of students with learning disabilities, their relation with the social efficiency, and the most common learning disabilities, as well as the study of Hidrous \& Al-Farra, (2011) which pointed out that there are statistically significant differences between the pre and post measurements of the achievement motivation scale in favor of the post measurement, and that there are statistically significant differences between the two groups in favor of the experimental group of self-confidence. In addition, it agrees with the study of Agnew, Dorn, and Eden, (2004) which aimed at measuring the impact of intensive training through a treatment program for the hearing treatment and reading skill. The children showed a remarkable development in the process of hearing treatment. Besides, its agreement with the study of Poon-McBrayer \& Mcbeayer, (2014) that handled the experiments of Chinese parents in supporting their children with learning disabilities (Dyslexia) which pointed out that parents emotional support reduces self-blame and sadness among these children and increases their knowledge and abilities. It also agrees with the study of (Hasouneh, 2004) that aimed at identifying the effectiveness of social skills training program in enhancing self-concept with all its dimensions as one of the learning disabilities aspects. One of the most important results was that there are statistically significant differences in favor of the group of self-concept with all its dimensions.

Results related to the third question showed that there are differences between the pre and 
post measurements in favor of the post-measurement which indicates the impact of the training program used in enhancing the academic achievement of Arabic language and mathematics skills for the sample of the study. The researchers attribute this to the fact that the training program has a positive impact on raising the level of academic achievement and directing the students' interest toward increasing the motivation of learning reflected remarkably on their achievement, Moreover; the impact of the training program applied over the sample of the study led to increasing the individual training rate which was also reflected on their achievement. The current study agrees as well with the study of Ukeli, (2013) in which he studied the relationship between parents and their children's achievement in mathematics who suffer from visual disability. He studied the impact of parental intervention on achievement. He investigated the relationship between the parental participation at home and school and the achievement in mathematics for students with visual disabilities. The results showed that parental participation has a positive impact on the achievement in mathematics. The current study goes with the study of Thrnton, (2015) which addressed the relationship between parental participation and the academic achievement of students with special needs, it pointed out that focusing on homework and the parental participation in homework of students with special needs and their relation with the academic achievement. It also agrees with the study of Afolabi, (2014) which highlighted the concept of parental participation and the possibility of its achievement within a tangible context of comprehensive education. The most important results of this study was the existence of a strong meaningful relationship between the parental participation and the academic achievement, and the parents' believes, experiences and expectations which are considered important elements to support the outputs of the learning of children with special needs. It also agrees with the study of Abu Zaytoun, (2004) which aimed at building a training program of studying skills for students with learning disabilities, and measuring the effect of the enhancement in their studying skills. The results showed that there are statistically significant differences in the academic achievement in favor of the experimental group attributed to the training program used in studying. It also agrees with the study of Zhang, Hsu, Kwok, Benz, \& Bowman-Perrott, (2011) which aimed at testing the variables associated with race/ethnicity and socioeconomic status and their impact on the parental relationships at school and at home and how this affects school activities, the expectations from a child.

The result related to the fourth question indicates the existence of a statistically positive correlation between the familial participation and the reduction of learning disabilities aspects. This is explained by the great role of parental participation and families' care in reducing learning disabilities aspects. The more students with learning disabilities receive training, care and follow-up from the families the more the aspects of learning disabilities were reduced. Taking into account the assumption that family's care and participation are based on the children's needs to face their learning disabilities, identifying them and including them in an individual educational program for students with learning disabilities. This result disagrees with the study of Aldrete-Phan, (2002) which aimed at comparing the learning responses of children with and without learning disabilities, and comparing the stress responses of children with and without learning disabilities. The results showed that students with learning disabilities who receive special educational services have acquired negative results in their 
learning responses.

The result related to the fifth question showed that there is a statistically significant positive correlation between the familial participation and the academic achievement. As the researchers explain this, creating training and learning opportunities which activate and achieve the familial participation have a great impact in raising the academic achievement, this goes in line with the educational literature that addressed the topic of academic achievement. The parents care for their children's education, the parents' continuous motivation for their children, and the time allocated for homework play an important effective role in the academic development. The familial stability and cooperation are important effective factors in the achievement of students with learning disabilities. Families that suffer familial problems, disputes and weak relations, in which the father or the mother treat the children in a cruel manner, affect the children's readiness to learn and their academic achievement. The educational and economic level of the family is positively correlated with the academic achievement. Children of the educated class have better opportunities of achievement. The better the economic and educational level of the family is the better their children's achievement becomes. This is because parents with high educational level encourage and motivate their children by providing them with the needed instructions that help them when they need as for parents are aware of this important role. Studies have also proved the role of the economic level of the family and its positive impact on the students' achievement through offering financial motivations to their children for the high achievements they achieve. This result also agrees with the study of Alice and Alan, (2011) which handled the impact of parental intervention on the academic achievement of children with reading and writing learning disabilities. The results showed that the parental participation and cooperation with school and education at home led to enhancing their children's skills which was reflected on their academic achievement. It also agrees with the study of Carlon and Hopper, (2004) which indicated that there is a relationship between the participation and increasing the academic achievement of the members of the study sample.

\section{Recommendations}

Based on the results of the study, the researchers recommend the following:

1- Preparing training programs to develop the two dimensions of the social and emotional preparedness (social relations, life skills or independence) separately, within a specialized program.

2- Applying the training program developed in this study through teachers and educational instructors.

3- Applying the training program over various categories from the study sample with different ages to ensure the effectiveness of the program.

4- Activating the familial participation at the schools of learning disabilities due to its positive impact on raising the academic achievement and reducing learning disabilities 
aspects.

\section{References}

Abu Zeitoun, J. (2004). The Impact of a Training Program on the Development of Academic Skills, Achievement and Academic Self-concept among Students with Learning Disabilities. Unpublished PhD thesis, University of Jordan, Amman.

Afolabi, O. E. (2014). Parents involvement in inclusive education: An empirical test for the psycho-educational development of learners with special educational needs (SENs). International Journal of Educational Administration and Policy Studies, 6(10), 196-208.

Agnew, J. A., Dorn, C., \& Eden, G. F. (2004). Effect of intensive training on auditory processing and reading skills. Brain and Language, 88(1), 21-25. https://doi.org/10.1016/S0093-934X(03)00157-3

Al-Batal, Z. (2005). Assessment of the Skills of Teachers of Students with Learning Disabilities in the Preparation and Implementation of Direct Teaching Method. Arab Journal of Special Education, Arab Academy for Special Education, Riyadh.

Aldrete-Phan, C. N. (2002). A comparison of stress responses of children with and without learning disabilities. Dissertation Abstracts International, Section A: Humanities and Social Sciences, 62(11-A), 3739.

Al-Hiary, G. (2012). Characteristics of Behavioral or Emotional Disorders of Children and Adolescents ( $1^{\text {st }}$ Ed.). Dar Al-Fikr Publishers \& Distributers, Jordan: Amman.

Alice,c. L., Alan, H. (2011). Parental paired-reading intervention for Chinese dyslexic children: using curriculum-based measurement to assess responsiveness-to- instruction. University of Amsterdam, Wiley online library, 17.2-18.

Al-Khatib, J. (2009). Families of Disabled Children, Guidance, Training and Support Strategies ( $1^{\text {st }}$ Ed.). Dar Wael for Publishing, Jordan: Amman.

Al-Kurdi, M. (2006). The Societal Participation Assessment in the Educational Studies in Riyadh, Journal of Reading and Knowledge, 6(2).

-Almakanin, H. A., Al-Zo'ibi, Z. H., \& Beirat, M. A. (2018). Level of Support by Collaborator Teacher for Field Training in Special Education at Jordanian Universities. International journal of special education, 33(1).

Al-Makanin, H., Abdullat, B., \& Al-Njadat, H. (2014). Behavioral Problems of Students with Learning Disabilities and its Relation with the Social Efficiency from the Teachers and Peers' Perspective. Jordanian Journal of Educational Sciences, 10(4).

Al-Rousan, F. (2010). The Psychology of Unusual Children (Introduction to Special Education). (8 ${ }^{\text {th }}$ Ed.). Dar Al-Fikr Publishers \& Distributers, Amman-Jordan. 
Al-Sartawi, Z., \& Al-Sartawi, A., A. (1988). The Developmental and Academic Learning Disabilities. Golden Pages Bookshop. Riyadh-KSA.

Al-Shahrani, A. (1996). The Factors Affecting Students' Achievement. Journal of Education, $18(6)$.

Al-Sinani, O. (2005). The Familial Participation in the Educational Process Management as Perceived by Primary Schools Managers in Masqat Governorate, unpublished master thesis, Yarmouk University, Irbid, Jordan.

Al-Zayat, F. (2007). Lecture: Learning Disabilities in our Schools.

Calson, M., \& Hopper, J. (2004). Increasing the Self-Concept of Elementary School Students with Learning Disabilities. Retrieved, January 4, 2011 from: http:www.wa-schoolcounselor.org

Da'na, Z. (2011). Special Education (Early Childhood from Birth till Eight Years Old: Strategies for Positive Outcomes) ( ${ }^{\text {st }}$ Ed.). Dar Al-Fikr Publishers \& Distributers, Jordan: Amman.

Eheart, B., \& Ciccone, J. (1982). Special needs of low income mothers of developmentally delayed children. American Journal of Mental Defficiency, 34, 55-68.

Grossman, G. (2010). Teacher Perceptions and Childrens School Achievement: Evidence. Booke.

Guralnick,M. (1997). The effectiveness of early intervention Baltimore, MD: Brookes

Hanafi, A., \& Rafeeq, S. (2010). The Role of the Family in the Education of Members with Special Needs (Reality - Ambition), a worksheet presented in the Conference of Guests and Summer Festival in Hail, Saudi Arabia.

Hasouneh, N. (2004). The Impact of a Social Skills Training Program on the Development of Self-concept, Social Efficiency and the Achievement of Students with Learning Disabilities. Unpublished master thesis, University of Jordan, Amman.

Heimdahl Mattson, E., Fischbein, S., \& Roll-Pettersson, L. (2010). Students with reading difficulties/dyslexia: a longitudinal Swedish example.International Journal of Inclusive Education, 14(8), 813-827. https://doi.org/10.1080/13603110902721662

Hidrous, Y., \& Al-Farra, M. (2011). The Impact of Using some Active Learning Strategies on the Level of Achievement Motivation, Self-confidence and Academic Achievement for Students with Slow Learning. Journal of Al-Azhar University in Gaza, Series of Humanitarian Sciences, 13(1A).

Ismail, M. (2012). Education for Students with Special Needs in Integration Classes (1st ed.). Dar Al-Fikr Publishers \& Distributors, Jordan: Amman.

Jirar, J., \& Al-Miladi, A., A.(2008). Learning Disabilities. Alexandria, University Youth Foundation. 
Jirwan, F., Al-Khamrah, H., Sadiq, L., Tabbal, S., Amairah, M., Miqdadi, Q., Aliwat, S., Al-Ali, S., Al-Hiary, G., Fawaz, U., Al-Zare', N., \& Al-Jabiri, M. (2013). Students with Special Needs (Introduction to Special Education) $\left(1^{\text {st }}\right.$ Ed.). Dar Al-Fikr Publishers \& Distributers, Jordan: Amman.

Lerner, Janet. W. (2003). Children with Learning Disabilities. Second Ed.Houghhton Mifflin Company, Atlants.

Mas'udi, M., \& Abd Al-Wahab, D. (2013). The Effect of a Training Program to Stimulate Internal Academic Motivation in Self-esteem and Academic Achievement among a Sample of Middle School Students with Learning Disabilities in Ta'if City. Arab Studies in Education and Psychology, 37, Part I.

McDonnall, M. C., Cavenaugh, B. S., \& Giesen, J. M. (2012). The relationship between parental involvement and mathematics achievement for students with visual impairments. The Journal of Special Education, 45(4), 204-215. https://doi.org/10.1177/0022466910365169

Ministry of Education in Jordan. (2010). Educational Packages of Third Grade, Management of Education, Special Education Directorate, Department of Learning Disabilities and Articulation and Language Disorders, $1^{\text {st }}$ edition, Amman: Jordan.

Poon-McBrayer, K. F., \& McBrayer, P. A. (2014). Plotting Confucian and disability rights paradigms on the advocacy-activism continuum: experiences of Chinese parents of children with dyslexia in Hong Kong. Cambridge Journal of Education, 44(1), 93-111. https://doi.org/10.1080/0305764X.2013.860084

Sartawi, Z. (1995). The Scale of Learning Disabilities for Primary School Students. A published research by the Educational Research Center, Faculty of Education, King Saud University, No. 104. 37.

Taylor, R. (2006). Assessment of exceptional students: Educational and psychological procedures $\left(7^{\text {th }}\right.$ ed $)$. Boston: pearson.

-Thrnton,R.(2015).Parental Involvement and Academic Achievement.Unpublished Master Thesis.Governors State University.USA. All Capstone Projects. 114.

Ukeli, V. T., \& Akem, I. A. (2013). Parental Role in Mathematics Achievement of Visually Impaired Students in Benue State. Journal of Educational and Social Research, 3(5), 25. https://doi.org/10.5901/jesr.2013.v3n5p25

Ulaimat, I., \& Fayiz, M. (2012). The Impact of a Linguistic Training Program to Develop the Receptive Language Skills for Pre-school Children with Language Disorder among a Jordanian Sample. The Jordanian Journal of Educational Sciences, 8(1).

Zhang, D., Hsu, H. Y., Kwok, O. M., Benz, M., \& Bowman-Perrott, L. (2011). The impact of basic-level parent engagements on student achievement: Patterns associated with race/ethnicity and SES. Journal of Disability Policy Studies, http://dx.doi.org/1044207310394447 


\section{Macrothink}

\section{Copyright Disclaimer}

Copyright for this article is retained by the author(s), with first publication rights granted to the journal.

This is an open-access article distributed under the terms and conditions of the Creative Commons Attribution license (http://creativecommons.org/licenses/by/3.0/). 